\title{
Targeting the DPP-4-GLP-1 pathway improves exercise tolerance in heart failure patients: a systematic review and meta-analysis
}

\author{
Chengcong Chen ${ }^{1 \dagger}$, Ying Huang ${ }^{2 \dagger}$, Yongmei Zeng ${ }^{3}$, Xiyan $L u^{1}$ and Guoqing Dong ${ }^{1 *}$ (D)
}

\begin{abstract}
Background: The most significant manifestation of heart failure is exercise intolerance. This systematic review and meta-analysis was performed to investigate whether dipeptidyl peptidase-4 (DPP-4) inhibitors or glucagon-like peptide 1 receptor agonists (GLP-1 RAs), widely used anti-diabetic drugs, could improve exercise tolerance in heart failure patients with or without type 2 diabetes mellitus.

Methods: An electronic search of PubMed, EMBASE and the Cochrane Library was carried out through March 8th, 2019, for eligible trials. Only randomized controlled studies were included. The primary outcome was exercise tolerance [6-min walk test (6MWT) and peak $\mathrm{O}_{2}$ consumption], and the secondary outcomes included quality of life (QoL), adverse events (AEs) and all-cause death.

Result: After the literature was screened by two reviewers independently, four trials (659 patients) conducted with heart failure patients with or without type 2 diabetes met the eligibility criteria. The results suggested that targeting the DPP-4-GLP-1 pathway can improve exercise tolerance in heart failure patients [MD $24.88(95 \% \mathrm{Cl} 5.45,44.31)$, $P=0.01]$ without decreasing QoL $[S M D-0.51(95 \% \mathrm{Cl}-1.13,0.10), P=0.10]$; additionally, targeting the DPP-4-GLP-1 pathway did not show signs of increasing the incidence of serious AEs or mortality.

Conclusion: Our results suggest that DPP-4 inhibitors or GLP-1 RAs improve exercise tolerance in heart failure patients. Although the use of these drugs for heart failure has not been approved by any organization, they may be a better choice for type 2 diabetes mellitus patients with heart failure. Furthermore, as this pathway contributes to the improvement of exercise tolerance, it may be worth further investigation in exercise-intolerant patients with other diseases.
\end{abstract}

Keywords: Heart failure, GLP-1 receptor agonist, DPP-4 inhibitor, Exercise tolerance

\section{Background}

Heart failure (HF) is a complex clinical syndrome resulting from structural or functional impairment of ventricular filling or the ejection of blood, and the lifetime risk of HF ranges from 20 to $46 \%$ [1]. Those with diabetes mellitus have at least double the risk. HF patients with diabetes are associated with a higher rate of

\footnotetext{
* Correspondence: szdonggq@163.com

${ }^{\dagger}$ Chengcong Chen and Ying Huang contributed equally to this work.

${ }^{1}$ Section of Endocrinology, Department of Pediatrics, Shenzhen Maternity \&

Child Healthcare Hospital, Shenzhen, China
}

Full list of author information is available at the end of the article hospitalization and mortality [2, 3]. Although mortality has declined due to the use of angiotensin-converting enzyme inhibitors, beta-blockers and spironolactone [4], approximately $50 \%$ of patients die 5 years after diagnosis [5]. Standard treatments for patients with HF and diabetes are lacking [6]. Moreover, HF results in another serious issue among patients. Dyspnoea and fatigue, the most common symptoms among HF patients, can result in exercise intolerance [5], which not only contributes to decreasing quality of life (QoL) among patients but also results in impairment of working capacity, further increasing the economic burden [7]. However, very few

(c) The Author(s). 2019 Open Access This article is distributed under the terms of the Creative Commons Attribution 4.0 International License (http://creativecommons.org/licenses/by/4.0/), which permits unrestricted use, distribution, and reproduction in any medium, provided you give appropriate credit to the original author(s) and the source, provide a link to the Creative Commons license, and indicate if changes were made. The Creative Commons Public Domain Dedication waiver (http://creativecommons.org/publicdomain/zero/1.0/) applies to the data made available in this article, unless otherwise stated. 
studies have focused on exercise tolerance in this population.

A body of literature demonstrates that lower healthrelated QoL is associated with a higher mortality rate among HF patients $[5,8]$. In particular, QoL was significantly reduced in HF patients with exercise intolerance. Thus, improvements in exercise tolerance may benefit HF patients. Although studies on the DPP-4-GLP-1 pathway and exercise tolerance are limited, previous studies indicated that GLP-1 can recruit microvasculature to skeletal muscle [9] and induce mitochondrial activity, which enhances $\mathrm{O}_{2}$ consumption $[10,11]$. Additionally, a study indicated that a DPP-4 inhibitor improved exercise tolerance and mitochondrial biogenesis by activating GLP-1 receptor signalling [12]. The greater peak $\mathrm{O}_{2}$ consumption is related to better exercise tolerance [13].

Dipeptidyl peptidase-4 (DPP-4) inhibitors and glucagon-like peptide-1 receptor agonists (GLP-1 RAs) are used to treat type 2 diabetes mellitus (T2DM) in adults $[14,15]$. Glucagon-like peptide-1 (GLP-1) is an incretin hormone released from the gut, and it can be cleaved by dipeptidyl peptidase- 4 within 2 min $[16,17]$. Inhibiting DDP-4 can prolong the action of GLP-1, while a GLP-1 RA is a peptide similar to GLP-1 and can resist degradation by DPP-4. Thus, both DPP-4 inhibitors and GLP-1 RAs have the same pharmacological effect of prolonging the activation of the GLP-1 receptor [18]. A previous study indicated that abnormal glucose metabolism was associated with exercise intolerance [19], and recently, some clinical trials investigated the effect of these drugs in HF patients [4, 20-23]. It is worth investigating whether DPP-4 inhibitors/GLP-1 RAs improved exercise tolerance in HF patients.

As the effect of targeting the DPP-4-GLP-1 pathway on exercise tolerance in humans with HF remains unclear, we performed this systematic review and metaanalysis to investigate whether DPP-4 inhibitors/GLP-1 RAs could improve exercise tolerance in HF patients. Short-term treatment may have limited efficacy, as GLP1 agonist treatment is usually initiated at low doses and increases to higher doses based on clinical response, with a likely dosage adjustment after 1 month [24, 25]; thus, a minimum treatment duration of 1 month will be needed.

\section{Methods}

\section{Search strategy}

We performed this systematic review and meta-analysis based on the Preferred Reporting Items for Systematic Reviews and Meta-Analyses (PRISMA) statement [26]. An electronic search in the PubMed, EMBASE and Cochrane Library databases was carried out through March 8th, 2019, for eligible trials with no language restrictions. The search strategy mixed medical subject heading $(\mathrm{MeSH})$ and free-text words (Dipeptidyl Peptidase IV Inhibitors OR Alogliptin OR Anagliptin OR Linagliptin OR Saxagliptin OR Sitagliptin OR Vildagliptin) OR (Glucagon-like peptide 1 receptor agonist OR Albiglutide OR Exenatide OR Dulaglutide OR Semaglutide OR Liraglutide OR Lixisenatide OR Taspoglutide OR Benaglutide) AND (Heart Failure) AND (RCT Filter). The details are shown in Additional file 1. A manual search of references of systematic reviews and meta-analyses was also performed.

\section{Eligibility criteria}

Randomized, controlled trials were included if they involved adults aged 18 years or over who had HF. The intervention group needed to treat patients with glucagon-like peptide- 1 agonist or dipeptidyl peptidase- 4 inhibitor, and the minimum duration of treatment needed to be no less than 1 month.

Trials were excluded if they (1) were ongoing trials; (2) did not have a full text; (3) were randomized crossover trials; and (4) did not measure exercise tolerance, including the 6-min walk test $(6 \mathrm{MWT})$ and/or peak $\mathrm{O}_{2}$ consumption.

\section{Study selection and data extraction}

Two reviewers (Chen and Huang) selected records independently. Consultation with a third researcher was necessary to make a final determination when discrepancies occurred. Data were extracted from eligible trials with a data collection form that had been prepared previously. The following data were collected:

(1) Authors, years of publication, and study design; (2) Sample size, sex ratio, age, and the New York Heart Association (NYHA) functional class; (3) intervention setting and duration of treatment; (4) type 2 diabetes mellitus (T2DM) status, additional anti-diabetic drugs, and myocardial infarction history; (6) baseline and endpoint characteristics of exercise tolerance assessment (6MWT, peak $\mathrm{O}_{2}$ consumption) and QoL; and (7) allgrade AEs and all-cause deaths. If more than one paper was published using data from the same trial, data from the longest follow-up associated with our primary outcomes or secondary outcomes were extracted.

All data were transformed to mean change \pm standard deviation $(\mathrm{SD})_{\text {change }}$ when the data followed a normal distribution. The following formula was used:

$$
\begin{aligned}
\mathrm{SD}_{\text {change }}=\text { square root } & {\left[\left(\mathrm{SD}_{\text {pre-treatment }}\right)^{2}+\left(\mathrm{SD}_{\text {post-treatment }}\right)^{2}\right.} \\
& \left.-\left(2 \mathrm{R} \times \mathrm{SD}_{\text {pre-treatment }} \times \mathrm{SD}_{\text {post-treatment }}\right)\right]
\end{aligned}
$$

$\mathrm{R}$ can be determined by the full data that were reported in a similar study, and it can be calculated by the formula [27]. 


$$
\begin{aligned}
\mathrm{R}= & {\left[\left(\mathrm{SD}_{\text {pre-treatment }}\right) 2+\left(\mathrm{SD}_{\text {post-treatment }}\right)^{2}-\left(\mathrm{SD}_{\text {change }}\right)^{2}\right] / } \\
& {\left[2 \times \mathrm{SD}_{\text {pre-treatment }} \times \mathrm{SD}_{\text {post-treatment }}\right] }
\end{aligned}
$$

If the relevant data were unavailable, $\mathrm{R}$ could be assumed to be 0.5 [28].

If the trial reported only $95 \% \mathrm{CI}$ without the SD, we used the formula below to infer the SD.

$$
95 \% \mathrm{CI}=\text { mean } \pm 1.96 \mathrm{SE}
$$

$\mathrm{SD}=\mathrm{SE} \times$ square root $(\mathrm{N})$, where $\mathrm{N}$ represents the sample size of the trial.

\section{Data analysis}

We used RevMan 5.3 (The Nordic Cochrane Centre) to conduct the meta-analysis, and pooled mean change $_{\text {and }}$ $\mathrm{SD}_{\text {change }}$ were obtained as summary data. If an outcome was measured by different methods, we used the standardized mean difference (SMD) or applied the mean difference (MD). The results were considered statistically significant when $P$ values $\leq 0.05$ were presented in forest plots. The $\mathrm{I}^{2}$ test was used to evaluate heterogeneity. Values ranged from 0\% (homogeneity) to 100\% (high heterogeneity), and $\mathrm{I}^{2} \geq 50 \%$ indicated significant heterogeneity. If the heterogeneity was not significant, the results from the fixed-effects model and the randomeffects model were similar. When the heterogeneity was significant, the random-effects model was used.

The primary outcome was exercise tolerance, which was measured in a standardized way by a 6 -min walk test (6MWT) and peak $\mathrm{O}_{2}$ consumption $[29,30]$. Secondary outcomes included QoL, AEs and all-cause death.

\section{Risk of bias and sensitivity analysis}

We used the Cochrane Collaboration's tool to assess the risk of bias by two reviewers independently (Chen and Huang). To test the stability of the results, a range of sensitivity analyses were carried out: 1) an analysis including only trials using the double-blinding method, as open-label trials have a high risk of performance bias; 2) an analysis using different $\mathrm{R}$ values [28, 30]; and 3) a meta-analysis of QoL including only the trials using the Minnesota Living with HF Questionnaire (MQOL), as it has the opposite interpretation as the Kansas City Cardiomyopathy Questionnaire (KCCQ).

\section{Results}

A total of 2897records from eligible trials were identified and selected, as shown in Fig. 1. Five hundred ninetyone records were excluded because of duplication. After screening titles and abstracts, 2258 irrelevant records were excluded, and the full texts of the remaining $48 \mathrm{pa}$ pers were assessed. Consequently, 4 trials (17 publications) met the eligibility criteria in the end.

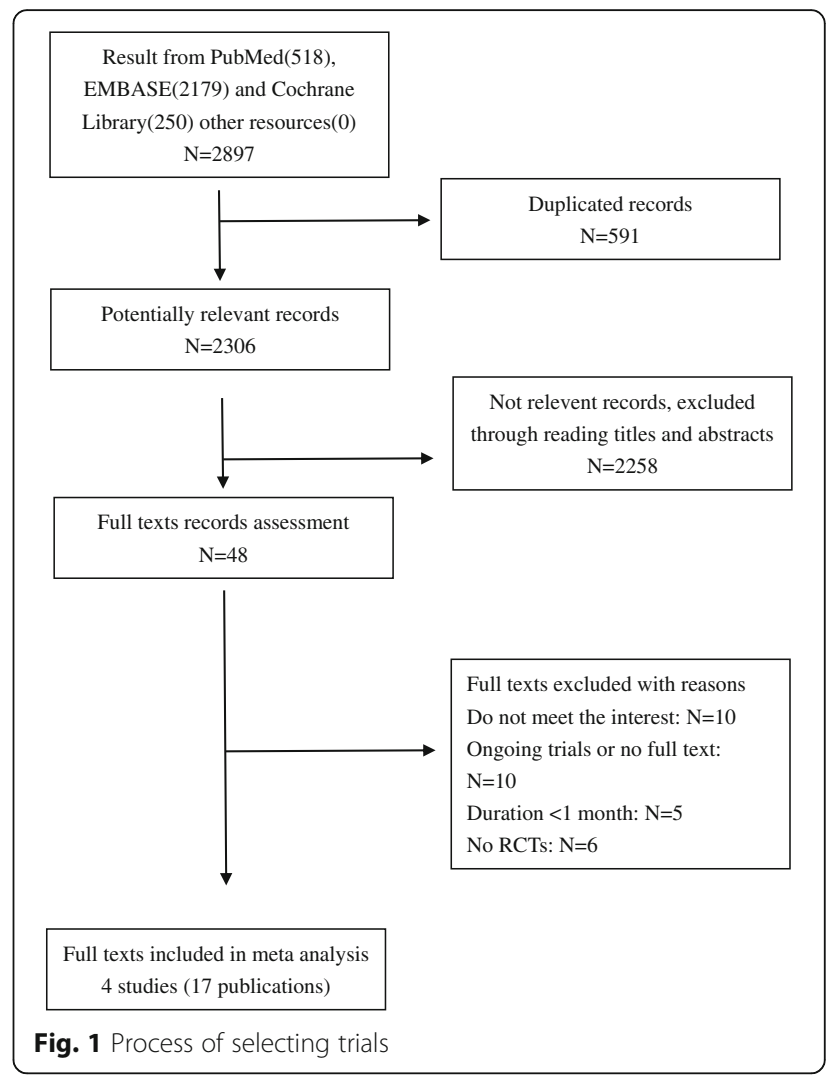

\section{Study characteristics}

The characteristics of the 4 included trials are shown in Table 1 . These trials were all published in 2016, and the sample sizes were between 36 and 300, with the duration of treatment ranging from 12 weeks to 52 weeks. One trial followed an open-label design, and the remaining 3 were double-blinded trials. Of all four eligible trials, 1 trial investigated both GLP-1 agonists and DPP-4 inhibitors [22], and 3 trials studied GLP-1 agonists [4, 20, 21]. In particular, 1 trial included only patients with a previous history of acute myocardial infarction [22]. Four studies reported pre-intervention and post-intervention or $6 \mathrm{MWT}_{\text {change }}$ and $\mathrm{QoL}_{\text {change, }}$ and 1 trial reported peak $\mathrm{O}_{2}$ consumption.

\section{Risk of bias assessment}

The risk of bias is shown in Figs. 2 and 3. In an open-label trial [22], echocardiographs were read in a random order by an investigator who had no knowledge of the patients' blood pressure or other clinical data, so we determined blinding of outcome assessment as low risk. The reasons for each evaluation are shown in Additional file 2.

\section{Outcomes}

Of the 4 trials, outcomes were presented as the mean $(95 \% \mathrm{CI})$ in one trial [21] and as the mean $\pm \mathrm{SD} / \mathrm{SE}$ in 3 trials $[4,20,22]$. All data were transformed into the 
Table 1 Study characteristics

\begin{tabular}{|c|c|c|c|c|}
\hline Author, years & Study design & \multicolumn{2}{|l|}{ Patients } & Intervention \\
\hline Arturi2016 & $\begin{array}{l}\text { Open-label } \\
\text { RCT }\end{array}$ & \multicolumn{2}{|c|}{ 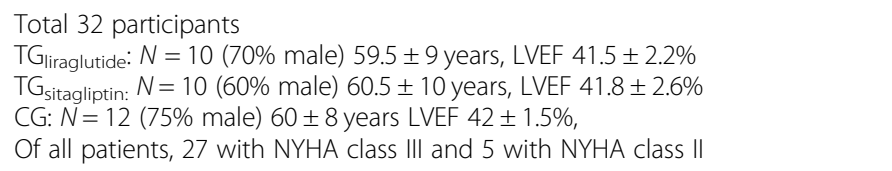 } & $\begin{array}{l}\text { liraglutide } 1.8 \mathrm{mg} \\
\text { VS sitagliptin } 100 \mathrm{mg} \\
\text { VS glargine insulin }\end{array}$ \\
\hline Jorsal2016 & $\begin{array}{l}\text { Double- } \\
\text { blinded RCT }\end{array}$ & \multicolumn{2}{|c|}{$\begin{array}{l}\text { Total } 241 \text { participates } \\
\text { TG: } N=122 \text { (89\%male) } 65 \pm 9.2 \text { years LVEF } 33.7 \pm 7.6 \% \text { NYHA class I-III } \\
\text { CG: } N=119 \text { (89\%male) } 65 \pm 10.7 \text { years LVEF35.4 } \pm 9.4 \% \text { NYHA class I-III }\end{array}$} & $\begin{array}{l}\text { liraglutide } 1.8 \mathrm{mg} \\
\text { VS placebo }\end{array}$ \\
\hline Lepore2016 & $\begin{array}{l}\text { Double- } \\
\text { blinded RCT }\end{array}$ & \multicolumn{2}{|c|}{$\begin{array}{l}\text { Total } 82 \text { participates } \\
\text { TG:N }=27 \text { (74\%male) } 58 \pm 10 \text { years LVEF } 31 \pm 8.3 \% \text { NYHA class }\|-\| I \\
\text { CG: } N=30 \text { ( } 70 \% \text { male) } 56 \pm 10 \text { years LVEF } 32 \pm 8.6 \% \text { NYHA class }\|-\| I \\
25 \text { participates in } 3.75 \mathrm{mg} \text { or } 15 \mathrm{mg} \text { was discontinued }\end{array}$} & $\begin{array}{l}\text { Albiglutide } 3.75 \text { mg, } 15 \text { mg,30 mg } \\
\text { VS placebo }\end{array}$ \\
\hline Margulies2016 & $\begin{array}{l}\text { Double- } \\
\text { blinded RCT }\end{array}$ & \multicolumn{2}{|c|}{$\begin{array}{l}\text { Total } 300 \text { participates } \\
\text { TG:N }=154(80 \% \text { male) } 62 \text { (52-68) years LVEF 25(20-33)\% NYHA class II-IV } \\
\text { CG:N }=146 \text { (77\%male) } 61 \text { (51-67) years LVEF } 25 \text { (19-32)\% NYHA class II-IV }\end{array}$} & $\begin{array}{l}\text { liraglutide; at } 0.6 \mathrm{mg} \text { SQ daily for } 7 \\
\text { days, } 1.2 \mathrm{mg} \text { SQ daily from day } 7 \\
\text { through day } 30,1.8 \mathrm{mg} \text { for the rest } \\
\text { VS placebo }\end{array}$ \\
\hline Author, years & Follow-up & $\begin{array}{l}\text { T2DM } \\
\text { status }\end{array}$ & Additional antidiabetic drugs & Myocardial infraction history \\
\hline Arturi2016 & 52 weeks & T2DM & Metformin or metformin and sulfonylurea & Prior acute myocardial infarction \\
\hline Jorsal2016 & 24 weeks & $\begin{array}{l}\text { With or } \\
\text { without } \\
\text { T2DM }\end{array}$ & $\begin{array}{l}\text { Any anti-diabetes drugs except GLP-1 receptor agonists, glitziness, } \\
\text { pramlintide or any DPP-4 inhibitor within } 30 \text { days prior to } \\
\text { randomization. Patients treat with fast-acting insulin were also } \\
\text { excluded }\end{array}$ & $\begin{array}{l}\text { Myocardial infarction within } 3 \text { months } \\
\text { were excluded }\end{array}$ \\
\hline Lepore2016 & 12 weeks & $\begin{array}{l}\text { Non- } \\
\text { T2DM }\end{array}$ & NR & No myocardial infarction \\
\hline Margulies2016 & 180 days & $\begin{array}{l}\text { With or } \\
\text { without } \\
\text { T2DM }\end{array}$ & $\begin{array}{l}\text { Ongoing GLP-1 agonists or DDP-4 inhibitors or thiazolidinedione } \\
\text { are not allowed. If patients treated with DDP-4, washed out for a } \\
\text { week was permitted }\end{array}$ & NR \\
\hline
\end{tabular}

NYHA class New York Heart Association functional class, T2DM Type 2 diabetes mellitus, TG Test group, CG Control group, NR Not reported

mean change $\pm \mathrm{SD}_{\text {change. }} \mathrm{R}$ was determined according to Lepore (2016) [20], as it reports pre-intervention outcomes, post-intervention outcomes and changes from baseline to the end-point. We also performed a sensitivity analysis between different values of $\mathrm{R}$ (shown in Additional file 3 ). The results showed that $\mathrm{R}$ did not impact the results of the meta-analysis except for the lower heterogeneity when $R=0.5$, so the following figures are displayed assuming $R=0.5$. As the open-label trial may have a high risk of performance bias, we performed a sensitivity analysis by removing the Arturi (2016) study to confirm the stability of the results (shown in Additional file 3), and the analysis yielded similar results. Because AEs were reported with different methods and only 1 patient died among the 3 trials, we presented AE data in a summarized table and did not pool the data into a meta-analysis.

\section{6 min walk test}

The impact on the 6MWT was investigated in 4 trials $[4,20-22]$. A total of 323 patients were randomly

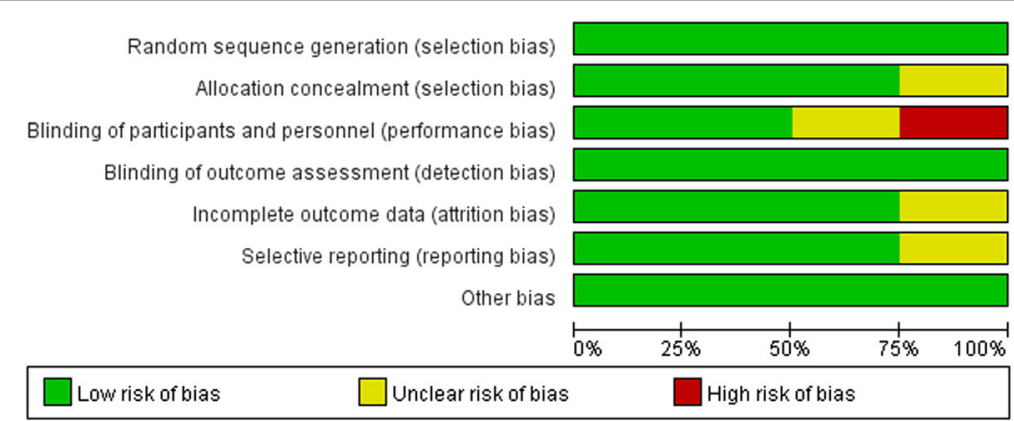

Fig. 2 Risk of bias graph of each trial 


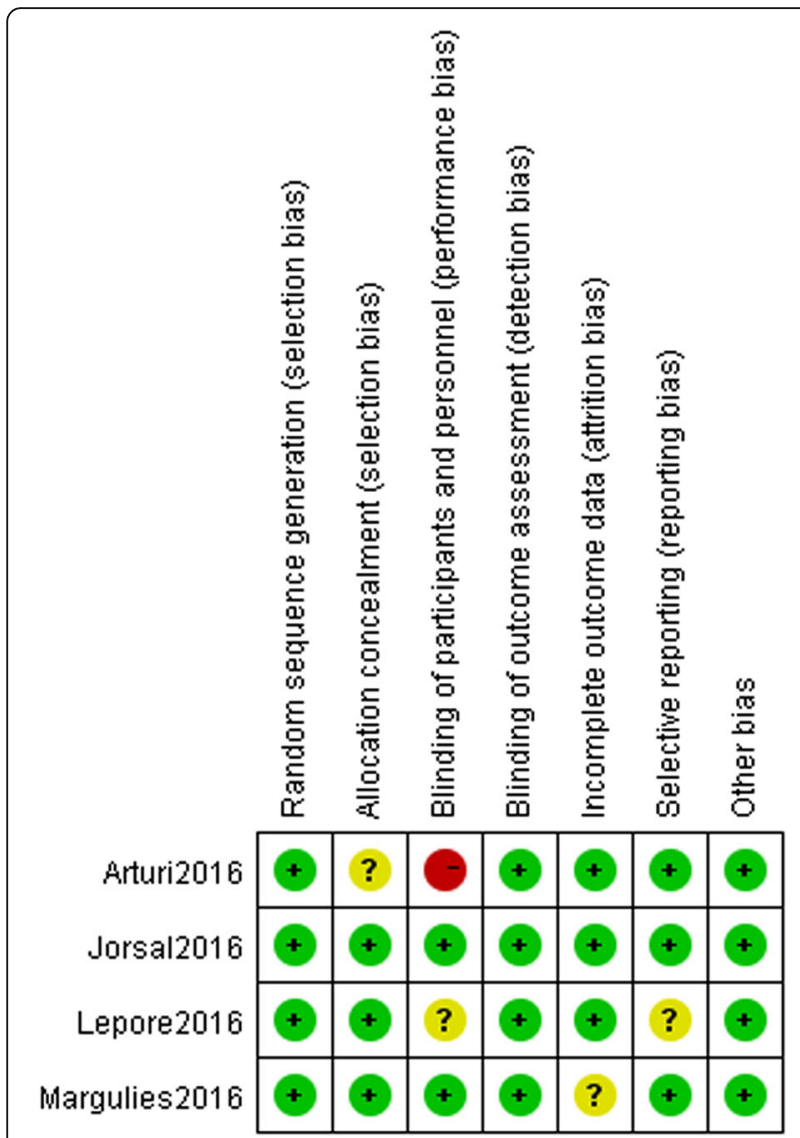

Fig. 3 Risk of bias summary of each trial

assigned to the experimental group, and 316 patients were assigned to the control group. In each trial, investigators calculated the walking distance in metres, so we used the MD in the meta-analysis. The results showed that there was a statistically significant difference between the two arms as shown in Fig. 4 [MD 24.88 (95\% CI $5.45,44.31), P=0.01]$. The sensitivity analysis confirmed the result (shown in Additional file 3); thus, DPP-4 inhibitors/GLP-1 RAs may benefit patients.

\section{Peak oxygen consumption}

One trial [20] (including 27 patients in the experimental group and 29 patients in the control group) investigated peak $\mathrm{O}_{2}$ consumption. The results showed that peak $\mathrm{O}_{2}$ consumption in the experimental group improved significantly compared with that of the placebo group [MD $1.5(\mathrm{SE}=0.7), P=0.024]$.

\section{Quality of life}

All eligible trials $[4,20-22]$ measured QoL. Three of the four used the MQOL $[4,20,22]$, and one trial used the KCCQ [21]. A high score on the MQOL indicates low QoL, but a high score indicates high quality on the KCCQ. To pool these 4 trials into a meta-analysis, we put experimental data from Margulies (2016) into a "control group" and put control data into an "experimental group" in the forest plot. Because of the different methods, we applied SMD in this situation. The results showed no difference between the two groups as shown in Fig. 5 [SMD -0.51 (95\% CI $-1.13,0.10), P=0.10]$. The sensitivity analysis showed that the treatment may improve patients' QoL but not in a stable way (shown in Additional file 3). Therefore, it was determined that using DPP-4 inhibitors or GLP-1 agonists in HF patients did not affect QoL.

\section{AEs and all-cause death}

The data were collected and are displayed in Table 2 . Different methods were used to collect AE data in each trial; thus, we did not perform a meta-analysis. Of all 4 trials, one reported neither death nor AEs (mild nausea in liraglutide-treated patients could be solved without treatment) [22], and only one study demonstrated that the number of non-serious gastrointestinal events and central nervous system (CNS) events in the GLP-1 group were significantly higher than that in the placebo group; however, there was no difference in the incidence of serious adverse events (SAEs) [4]. Nonetheless, the rest of the studies did not report statistically significant AEs associated with GLP-1 RAs. Further studies are warranted to confirm the safety of GLP-1 RAs among HF patients.

The number of deaths in the control groups was 0 in 3 trials [4, 20,22], and one patient died in the experimental group in 1 of the 3 trials [4]. Thus, we did not perform a meta-analysis. Another trial reported that 19 and 16 patients died in the experimental group and the control group, respectively, with no significant difference [21].

Overall, although we could assess the safety only through a table and not with statistical methods, DPP-4

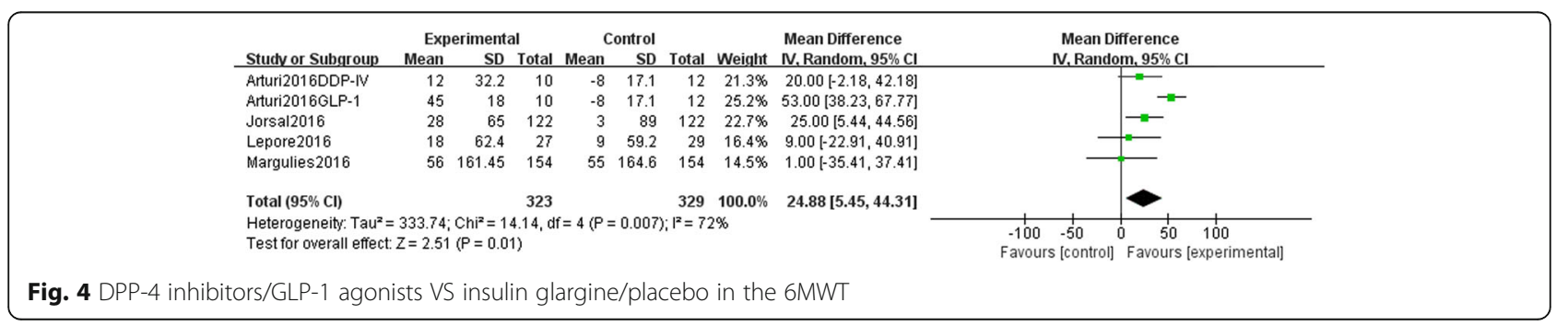




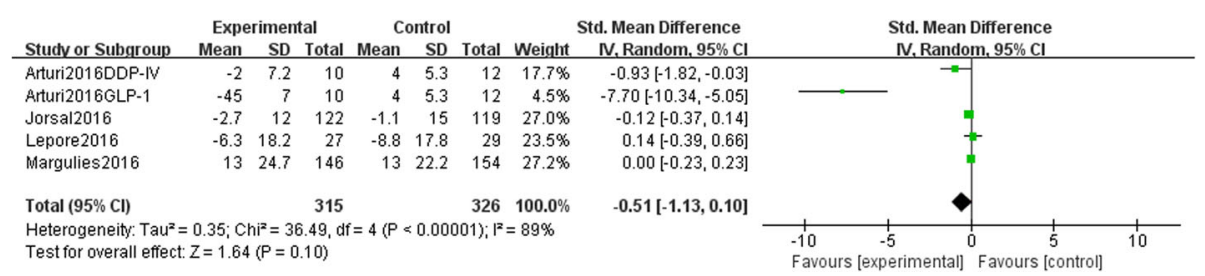

Fig. 5 DPP-4 inhibitors/GLP-1 agonists VS insulin glargine/placebo in QoL

inhibitors/GLP-1 agonists did not appear to increase mortality or SAE among HF patients.

\section{Discussion}

Dyspnoea and fatigue, which are the most common symptoms among HF patients, can result in exercise intolerance [5]. Exercise intolerance can decrease healthrelated QoL and contribute to poor prognosis. The $6 \mathrm{MWT}$ is a common method used to measure patients' exercise tolerance, while peak $\mathrm{O}_{2}$ consumption is another standard method $[29,30]$. In this systematic review and meta-analysis, the results of the $6 \mathrm{MWT}$ and peak $\mathrm{O}_{2}$ consumption suggested that DPP-4 inhibitors/GLP-1 RAs improve patients' exercise tolerance and did not reduce patients' QoL, with high heterogeneity among the results. In accordance with the Cochrane Handbook, we conducted a sensitivity analysis using the leave-one-out method by removing trials with specific characteristics that may have caused unstable results. The study characteristics table clearly showed that the Arturi (2016) study was most likely to cause instability because it was an open-label trial, while the others were all double-blinded trials. Moreover, the Arturi (2016) study enrolled only patients with T2DM with a history of acute myocardial infarction, which is significantly different from the populations in the other trials. The sensitivity analysis confirmed the stability of our outcome, as shown in Additional file 1. Additionally, Margulies (2016) used the KCCQ to measure QoL, while the other studies used the MQOL. As these two methods have opposite interpretations, we pooled them into a meta-analysis that may have resulted in unstable results. Thus, a sensitivity analysis was also conducted, and the results confirmed that the treatment did not decrease patients' QoL.

Although studies on the DPP-4-GLP-1 pathway and exercise tolerance are still limited, previous studies have demonstrated that GLP-1 can recruit microvasculature and induce mitochondrial activity in muscle $[9,10,12]$. Microvasculature is responsible for delivering oxygen, nutrients, and hormones to human skeletal muscle and removing metabolic products [31]. During exercise, the microvasculature plays a very important role in ensuring a sufficient supply of oxygen and nutrients; thus, the mitochondria can use oxygen and nutrients to generate ATP [13]. Targeting the DPP-4-GLP-1 pathway increases GLP-1 levels, thus recruiting microvasculature to muscle to ensure the supply of oxygen and nutrients and inducing mitochondrial activity. Better peak $\mathrm{O}_{2}$ consumption is correlated with better microvasculature function. Consequently, this series of reactions may result in improved exercise tolerance. Moreover, a study indicated that a DPP-4 inhibitor improved exercise

Table 2 All-cause death and adverse events

\begin{tabular}{|c|c|c|c|c|}
\hline & Treatment and control & Patients included in analysis & All cause death $(\mathrm{N})$, & Drug related adverse events (N) \\
\hline \multirow[t]{3}{*}{ Arturi2016 } & Liraglutide & 10 & 0 & 0 \\
\hline & Sitagliptin & 10 & 0 & 0 \\
\hline & Insulin glargine & 12 & 0 & 0 \\
\hline \multirow[t]{2}{*}{ Jorsal2016 } & Liraglutide & 122 & 1 & $\begin{array}{l}\mathrm{AE}\left(\text { cardiac }=13, \text { gastrointestinal }=80^{*}, \mathrm{CNS}=38^{*}, \text { other }=\right. \\
38(31.1 \%)), \\
\mathrm{SAE}(\text { cardiac }=12, \text { gastrointestinal }=0, \mathrm{CNS}=2, \text { other }=13)\end{array}$ \\
\hline & Placebo & 119 & 0 & $\begin{array}{l}\mathrm{AE}(\text { cardiac }=10, \text { gastrointestinal }=19, \mathrm{CNS}=15, \text { other }= \\
38), \\
\mathrm{SAE}(\text { cardiac }=3, \text { gastrointestinal }=1, \mathrm{CNS}=3, \text { other }=9)\end{array}$ \\
\hline \multirow[t]{2}{*}{ Lepore2016 } & Albiglutide & 27 & 0 & $A E=20, S A E=0$ \\
\hline & Placebo & 30 & 0 & $\mathrm{AE}=25, \mathrm{SAE}=4$ \\
\hline \multirow[t]{2}{*}{ Margulies2016 } & Liraglutide & 154 & 19 & Cardiac $=37 ;$ glycemic $=36 ;$ other $=35$ \\
\hline & Placebo & 146 & 16 & Cardiac $=34 ;$ glycemic $=28 ;$ other $=52$ \\
\hline
\end{tabular}

${ }^{*}$ means $P \leq 0.05$ compared with placebo 
tolerance by activating GLP-1 receptor signalling [12]. One trial reported peak $\mathrm{O}_{2}$ consumption in this systematic review, and the results showed that the experimental group was superior to the control group [20]. However, the authors of the trial indicated that it might be a spurious finding, as the 6MWT and QoL did not exhibit a significant improvement in this trial. In our metaanalysis, it was shown that the 6MWT could be improved after treatment. The 6MWT is another standard method to measure exercise tolerance in HF patients, and the result of the meta-analysis is more reliable than that of a single trial. Thus, we suggest that targeting the DPP-4-GLP-1 pathway benefits patients with limited exercise tolerance.

Our results did not show a significant improvement in health-related QoL after treatment. It is well recognized that QoL differs between sexes, ethnicities, age groups and so on [5]. Although improved exercise tolerance may affect QoL, the patient's living environment or other health problems such as obesity do as well [32, 33]. It should be noted that GLP-1 RAs can be used only through intramuscular injection, and the inconvenience and pain of injection may contribute to this finding.

Although DPP-4 inhibitors/GLP-1 RAs have been widely used in T2DM patients worldwide, there is a concern about AEs, as the Savor-TIMI 53 trial reported that saxagliptin increased the rate of hospitalization for HF [34]. However, the later studies all demonstrated that DPP-4 inhibitors can reduce mortality and do not increase the incidence of AEs [35-37], and the same findings were observed for GLP-1 RAs [38, 39]. Our results also showed that the treatment did not appear to increase the incidence of all-cause death or SAEs. The reason the rate of hospitalization for HF increased in the Savor-TIMI 53 trial may be due to the enrolled patients' basic disease, such as previous chronic kidney disease [40]. It should be noted that patients with a history of myocardial infarction (MI) may benefit from treatment. A trial in this systematic review, Arturi (2016), enrolled patients who had previous MI, and the results showed that patients can receive significant benefit from GLP-1 RA treatment. Previous studies have also indicated that this kind of patient may benefit from DPP-4 inhibitor treatment [41]. Chen, W. R. et al. demonstrated that liraglutide can improve left ventricular ejection fraction (LVEF) in patients with non-ST-segment-elevation myocardial infarction [42] and improve myocardial salvage and infarct size after ST-segment-elevation myocardial infarction [43]. Further studies on DPP-4 inhibitors and GLP-1 RAs in MI patients are needed.

Two trials did not report significant improvement, which may have been due to the patients' characteristics. A recent study showed that serum DPP-4 may be associated with the effect of DPP-4 inhibitors, and patients with serum DPP-4 between 455.6 and $625.5 \mathrm{ng} / \mathrm{mL}$ may be the most likely to obtain treatment benefits, such as a 3-year reduction in all-cause mortality [44]. Unfortunately, these trials did not measure serum DPP-4 or GLP-1 levels, which is likely a predictor of treatment efficacy.

In this systematic review, we included trials investigating the effect of DPP-4 inhibitors or GLP-1 RAs on HF patients with or without T2DM. The results suggested that these inhibitors had a positive effect on exercise tolerance and did not decrease QoL or show signs of increasing the incidence of all-cause death or SAEs. Previous studies have demonstrated that DPP-4 inhibitors and GLP-1 RAs may be associated with cardiovascular benefits $[45,46]$. DDP-4 inhibitors were reported to prevent cardiac diastolic dysfunction [47], ameliorate cardiac function in pressure overload heart failure [48], and attenuate the annual exacerbation of diastolic dysfunction [49]. Multiple lines of evidence have demonstrated the beneficial effects of GLP-1 RAs on heart function [50-52]. Meta-analyses have also suggested that these drugs can improve LVEF in patients with or without HF [53, 54]. Thus, targeting the DPP-4-GLP-1 pathway may be a potential strategy to improve heart function.

Exercise intolerance is well recognized in patients with T2DM and is known as a predictor of adverse prognosis [55]. Our study suggested that the use of DPP-4 inhibitors/GLP-1 RAs in HF patients with or without T2DM improves peak $\mathrm{O}_{2}$ consumption and 6MWT, contributing to better exercise tolerance. As the need for medical care in patients with $\mathrm{HF}$ and diabetes increases and the standard treatments are lacking [6], DPP-4 inhibitors and GLP-1 RAs, both anti-diabetic drugs, have shown beneficial effects in improving exercise tolerance in HF patients. Although these drugs have no indication for patients with HF, they may be better choices for patients with diabetes and HF. Furthermore, because this pathway contributes to improvement in exercise tolerance, it may be worth further investigation with exerciseintolerant patients with other diseases.

To our knowledge, this is the first systematic review and meta-analysis of randomized controlled trials to investigate the long-term treatment effect of DPP-4 inhibitors and GLP-1 RAs in HF patients. There are several limitations to this study. First, each trial had different collection methods for AEs. We could not perform a meta-analysis, but none of the studies reported an increased incidence of mortality or SAEs. Second, although DPP-4 inhibitors and GLP-1 RAs have the same pharmacological effect, DPP-4 inhibitors can be taken orally, which is more convenient than GLP-1 RAs, but we cannot compare the two types of drugs due to the limited number of trials. We hope that more studies can demonstrate the effect of DPP-4 inhibitors due to the convenience of oral drugs. Third, there were only 4 trials 
included in this meta-analysis, but these trials were all defined as high quality after assessment by the Cochrane Collaboration's tool. The results of the sensitivity analyses also confirmed the stability of our results. Finally, although targeting DPP-4-GLP-1 signalling may improve exercise tolerance in HF patients, it has not been approved by any organizations, and we cannot draw a conclusion regarding whether type 2 diabetes mellitus patients with HF could benefit more from treatment. Thus, further study is necessary.

\section{Conclusion}

DDP-4 inhibitors/GLP-1 RAs can improve exercise tolerance in HF patients, do not appear to increase the incidence of all-cause death or SAEs and do not decrease health-related QoL. As a result, current evidence shows that it may be a good choice for T2DM patients with HF.

\section{Supplementary information}

Supplementary information accompanies this paper at https://doi.org/10. 1186/s12872-019-01275-5.

Additional file 1. Search strategy, The search strategy in PubMed, EMBASE and Cochrane Library.

Additional file 2. Details of risk and bias assessment, This file included the supporting evidences of how we assessed the risk of bias.

Additional file 3. Sensitive analysis, We have conducted sensitive analyses of different study designed, $R$ value and questionnaires, this file presented the results.

\section{Abbreviations}

6MWT: 6-min walk test; AE: Adverse event; CNS: Central nervous system; DPP-4 inhibitor: Dipeptidyl peptidase-4 inhibitor; GLP-1 RA: Glucagon-like peptide 1 receptor agonist; HF: Heart failure; KCCQ: Kansas City cardiomyopathy questionnaire; MD: Mean difference; MI: Myocardial infarction; MQOL: Minnesota living with heart failure questionnaire; NYHA: New York heart association; QoL: Quality of life; SAE: Serious adverse event; SD: Standard deviation; SMD: Standardized mean difference; T2DM: Type 2 diabetes mellitus

\section{Acknowledgements}

The co-first authors Chengcong Chen and Ying Huang, has made substantial contributions to this work. Other authors were participated in the process of written revision, interpretation of data, etc. All authors mentioned in the meta-analysis are agreed to be mentioned in the manuscript.

\section{Authors' contributions}

CCC, HY, DGQ contributed to the design of the study; HY contributed to acquisition of data; CCC, HY, ZYM, LXY contributed to the interpretation of data; CCC and DGQ drafted the manuscript; CCC, HY, ZYM, LXY, DGQ contributed to critically revise the manuscript. All authors agree to be fully accountable for ensuring the integrity and accuracy of the work, and read and approved the final manuscript

\section{Funding}

All aspects of this study, design of the study, data collection, analysis, interpretation of data and writing the manuscript were funded by Sanming Project of Medicine in Shenzhen, SZSM201812056.

\section{Availability of data and materials}

The datasets used and/or analysed during the current study available from the corresponding author on reasonable request.
Ethics approval and consent to participate

Not applicable.

\section{Consent for publication}

Not applicable.

\section{Competing interests}

The authors declare that they have no competing interests.

\section{Author details}

'Section of Endocrinology, Department of Pediatrics, Shenzhen Maternity \& Child Healthcare Hospital, Shenzhen, China. ${ }^{2}$ School of Public Health, Chinese University of Hong Kong, Hong Kong, China. ${ }^{3}$ Section of Gastroenterology, Department of Pediatrics, Shenzhen Maternity\&Child Healthcare Hospital, Shenzhen, China.

Received: 25 March 2019 Accepted: 22 November 2019

Published online: 23 December 2019

\section{References}

1. Kenny HC, Abel ED. Heart failure in type 2 diabetes mellitus. Circ Res. 2019; 124(1):121-41.

2. Cavender MA, Steg PG, Smith SC Jr, Eagle K, Ohman EM, Goto S, Kuder J, Im K, Wilson PW, Bhatt DL, et al. Impact of diabetes mellitus on hospitalization for heart failure, cardiovascular events, and death: outcomes at 4 years from the reduction of Atherothrombosis for continued health (REACH) registry. Circulation. 2015:132(10):923-31.

3. Lawson CA, Jones PW, Teece L, Dunbar SB, Seferovic PM, Khunti K, Mamas M, Kadam UT. Association between type 2 diabetes and all-cause hospitalization and mortality in the UK general heart failure population: stratification by diabetic glycemic control and medication intensification. JACC Heart Fail. 2018;6(1):18-26.

4. Jorsal A, Kistorp C, Holmager P, Tougaard RS, Nielsen R, Hanselmann A, Nilsson B, Moller JE, Hjort J, Rasmussen J, et al. Effect of liraglutide, a glucagon-like peptide-1 analogue, on left ventricular function in stable chronic heart failure patients with and without diabetes (LIVE)-a multicentre, double-blind, randomised, placebo-controlled trial. Eur J Heart Fail. 2016 19(1):69-77.

5. Yancy CW, Jessup M, Bozkurt B, Butler J, Casey DE Jr, Drazner MH, Fonarow GC, Geraci SA, Horwich T, Januzzi JL, et al. 2013 ACCF/AHA guideline for the management of heart failure: a report of the American College of Cardiology Foundation/American Heart Association task force on practice guidelines. J Am Coll Cardiol. 2013;62(16):e147-239.

6. Arnold SV, Yap J, Lam CSP, Tang F, Tay WT, Teng THK, McGuire DK, Januzz $J$, Fonarow GC, Masoudi FA, et al. Management of patients with diabetes and heart failure with reduced ejection fraction: an international comparison. Diabetes Obes Metab. 2019:21(2):261-6.

7. Shafie AA, Tan YP, Ng CH. Systematic review of economic burden of heart failure. Heart Fail Rev. 2018;23(1):131-45.

8. Del Buono MG, Arena R, Borlaug BA, Carbone S, Canada JM, Kirkman DL, Garten R, Rodriquez-Miquelez P, Guazzi M, Lavie CJ, et al. Exercise intolerance in patients with heart failure: JACC state-of-the-art review. J Am Coll Cardiol. 2019;73(17):2209-25.

9. Subaran SC, Sauder MA, Chai W, Jahn LA, Fowler DE, Aylor KW, Basu A, Liu Z. GLP-1 at physiological concentrations recruits skeletal and cardiac muscle microvasculature in healthy humans. Clin Sci (Lond). 2014;127(3):163-70.

10. Morales PE, Torres G, Sotomayor-Flores C, Pena-Oyarzun D, Rivera-Mejias P, Paredes F, Chiong M. GLP-1 promotes mitochondrial metabolism in vascular smooth muscle cells by enhancing endoplasmic reticulum-mitochondria coupling. Biochem Biophys Res Commun. 2014;446(1):410-6.

11. Kang MY, Oh TJ, Cho YM. Glucagon-Like Peptide-1 Increases Mitochondria Biogenesis and Function in INS-1 Rat Insulinoma Cells. Endocrinol Metab (Seoul, Korea). 2015;30(2):216-20.

12. Takada S, Masaki Y, Kinugawa S, Matsumoto J, Furihata T, Mizushima W, Kadoguchi T, Fukushima A, Homma T, Takahashi M, et al. Dipeptidyl peptidase-4 inhibitor improved exercise capacity and mitochondria biogenesis in mice with heart failure via activation of glucagon-like peptide1 receptor signalling. Cardiovasc Res. 2016;111(4):338-47.

13. Kumar AA, Kelly DP, Chirinos JA. Mitochondrial dysfunction in heart failure with preserved ejection fraction. Circulation. 2019;139(11):1435-50. 
14. White WB, Cannon CP, Heller SR, Nissen SE, Bergenstal RM, Bakris GL, Perez AT, Fleck PR, Mehta CR, Kupfer S, et al. Alogliptin after acute coronary syndrome in patients with type 2 diabetes. N Engl J Med. 2013;369(14): 1327-35.

15. Marso SP, Daniels GH, Frandsen KB, Kristensen P, Mann JFE, Nauck MA, Nissen SE, Pocock S, Poulter NR, Ravn LS, et al. Liraglutide and cardiovascular outcomes in type 2 diabetes. N Engl J Med. 2016;375(4):311-22.

16. Yanagimachi T, Fujita Y, Takeda Y, Honjo J, Sakagami H, Kitsunai H, Takiyama Y, Abiko A, Makino Y, Kieffer TJ, et al. Dipeptidyl peptidase-4 inhibitor treatment induces a greater increase in plasma levels of bioactive GIP than GLP-1 in non-diabetic subjects. Mol Metab. 2017:6(2):226-31.

17. Stenlid R, Manell H, Halldin M, Kullberg J, Ahlstrom H, Manukyan L, Weghuber D, Paulmichl K, Zsoldos F, Bergsten P, et al. High DPP-4 concentrations in adolescents are associated with low intact GLP-1. J Clin Endocrinol Metab. 2018;103(8):2958-66.

18. Tahrani AA, Barnett AH, Bailey CJ. Pharmacology and therapeutic implications of current drugs for type 2 diabetes mellitus. Nat Rev Endocrinol. 2016;12(10):566-92.

19. Egstrup M, Kistorp CN, Schou M, Hofsten DE, Moller JE, Tuxen CD, Gustafsson I. Abnormal glucose metabolism is associated with reduced left ventricular contractile reserve and exercise intolerance in patients with chronic heart failure. Eur Heart J Cardiovasc Imaging. 2013;14(4):349-57.

20. Lepore JJ, Olson E, Demopoulos L, Haws T, Fang Z, Barbour AM, Fossler M, Davila-Roman VG, Russell SD, Gropler RJ. Effects of the novel long-acting GLP-1 agonist, Albiglutide, on cardiac function, cardiac metabolism, and exercise capacity in patients with chronic heart failure and reduced ejection fraction. JACC Heart Fail. 2016;4(7):559-66.

21. Margulies KB, Hernandez AF, Redfield MM, Givertz MM, Oliveira GH, Cole R, Mann DL, Whellan DJ, Kiernan MS, Felker GM, et al. Effects of Liraglutide on clinical stability among patients with advanced heart failure and reduced ejection fraction: a randomized clinical trial. Jama. 2016;316(5):500-8.

22. Arturi F, Succurro E, Miceli S, Cloro C, Ruffo M, Maio R, Perticone M, Sesti G, Perticone F. Liraglutide improves cardiac function in patients with type 2 diabetes and chronic heart failure. Endocrine. 2016:57(3):464-73.

23. Chen WJY, Diamant M, de Boer K, Harms HJ, Robbers LFHJ, van Rossum AC, Kramer MHH, Lammertsma AA, Knaapen P. Effects of exenatide on cardiac function, perfusion, and energetics in type 2 diabetic patients with cardiomyopathy: A randomized controlled trial against insulin glargine. Cardiovasc Diabetol. 2017;16(1):1

24. Liraglutide Medication Guidance. https://www.dailymed.n/m.nih.gov/ dailymed/searchcfm?labeltype=all\&query=liraglutide.

25. Exenatide Medication Guidance. https://www.dailymed.n/m.nih.gov/ dailymed/searchcfm?labeltype=all\&query=Exenatide.

26. Moher D, Liberati A, Tetzlaff J, Altman DG. Preferred reporting items for systematic reviews and meta-analyses: the PRISMA statement. Ann Intern Med. 2009;151(4):264-9 w264.

27. Cochrane Handbook. https://www.cochranelibrary.com/central\#.

28. Pearson MJ, Mungovan SF, Smart NA. Effect of aerobic and resistance training on inflammatory markers in heart failure patients: systematic review and meta-analysis. Heart Fail Rev. 2018;23(2):209-23.

29. Cohen-Solal A, Zannad F, Kayanakis JG, Gueret P, Aupetit JF, Kolsky H. Multicentre study of the determination of peak oxygen uptake and ventilatory threshold during bicycle exercise in chronic heart failure. Comparison of graphical methods, interobserver variability and influence of the exercise protocol. The VO2 French study group. Eur Heart J. 1991;12(10): 1055-63.

30. Guyatt GH, Sullivan MJ, Thompson PJ, Fallen EL, Pugsley SO, Taylor DW Berman LB. The 6-minute walk: a new measure of exercise capacity in patients with chronic heart failure. Can Med Assoc J. 1985;132(8):919-23.

31. Liu Z. Insulin at physiological concentrations increases microvascular perfusion in human myocardium. Am J Physiol Endocrinol Metab. 2007;293: E1250-5.

32. Purba FD, Hunfeld JAM, Fitriana TS, Iskandarsyah A, Sadarjoen SS, Busschbach JJV, Passchier J. Living in uncertainty due to floods and pollution: the health status and quality of life of people living on an unhealthy riverbank. BMC Public Health. 2018;18(1):782.

33. Ambak R, Mohamad Nor NS, Puteh N, Mohd Tamil A, Omar MA, Shahar $\mathrm{S}$, Ahmad NA, Aris T. The effect of weight loss intervention programme on health-related quality of life among low income overweight and obese housewives in the MyBFF@home study. BMC Womens Health. 2018;18(suppl 1):111.
34. Scirica BM, Bhatt DL, Braunwald E, Steg PG, Davidson J, Hirshberg B, Ohman $P$, Frederich R, Wiviott SD, Hoffman EB, et al. Saxagliptin and cardiovascular outcomes in patients with type 2 diabetes mellitus. N Engl J Med. 2013; 369(14):1317-26.

35. Toh S, Hampp C, Reichman ME, Graham DJ, Balakrishnan S, Pucino F, Hamilton J, Lendle S, lyer A, Rucker M, et al. Risk for hospitalized heart failure among new users of saxagliptin, sitagliptin, and other antihyperglycemic drugs: a retrospective cohort study. Ann Intern Med. 2016;164(11):705-14.

36. Morgan CL, Mukherjee J, Jenkins-Jones S, Holden SE, Currie CJ. Combination therapy with metformin plus sulphonylureas versus metformin plus DPP-4 inhibitors: association with major adverse cardiovascular events and allcause mortality. Diabetes Obes Metab. 2014;16(10):977-83.

37. Mclnnes G, Evans M, Del Prato S, Stumvoll M, Schweizer A, Lukashevich V, Shao Q, Kothny W. Cardiovascular and heart failure safety profile of vildagliptin: a meta-analysis of 17000 patients. Diabetes Obes Metab. 2015; 17(11):1085-92.

38. Zimmerman RS, Hobbs TM, Wells BJ, Kong SX, Kattan MW, Bouchard J, Chagin KM, Yu C, Sakurada B, Milinovich A, et al. Association of glucagonlike peptide-1 receptor agonist use and rates of acute myocardial infarction, stroke and overall mortality in patients with type 2 diabetes mellitus in a large integrated health system. Diabetes Obes Metab. 2017;19(11):1555-61.

39. Brown-Frandsen K, Emerson SS, McGuire DK, Pieber TR, Poulter NR, Pratley RE, Zinman B, Ranthe MF, Gron R, Lange $M$, et al. Lower rates of cardiovascular events and mortality associated with liraglutide use in patients treated with basal insulin: a DEVOTE subanalysis (DEVOTE 10) Diabetes Obes Metab. 2019;21(6):1437-44

40. Scirica BM, Braunwald E, Raz I, Cavender MA, Morrow DA, Jarolim P, Udell JA, Mosenzon O, Im K, Umez-Eronini AA, et al. Heart failure, saxagliptin, and diabetes mellitus: observations from the SAVOR-TIMI 53 randomized trial. Circulation. 2014;130(18):1579-88.

41. Connelly KA, Desjardins J, Advani A, Kabir G, Zhang Y, Advani SL, Yuen DA, Thai K, Gilbert RE. DPP-4 inhibition attenuates cardiac dysfunction and adverse remodelling following myocardial infarction in experimental diabetes. Can J Cardiol. 2011;27(5):S328.

42. Chen WR, Shen XQ, Zhang Y, Chen YD, Hu SY, Qian G, Wang J, Yang JJ, Wang ZF, Tian F. Effects of liraglutide on left ventricular function in patients with nonST-segment elevation myocardial infarction. Endocrine. 2016;52(3):516-26.

43. Chen WR, Chen YD, Tian F, Yang N, Cheng LQ, Hu SY, Wang J, Yang JJ, Wang SF, Gu XF. Effects of Liraglutide on Reperfusion Injury in Patients With ST-Segment-Elevation Myocardial Infarction. Circ Cardiovasc Imaging. 2016; 9(12):1.

44. Lourenco P, Silva S, Cunha F, Pereira J, Ribeiro A, Silva N, Guimaraes JT, Araujo JP, Bettencourt P. Dipeptidyl peptidase-IV in chronic heart failure with reduced ejection fraction. Int J Cardiol. 2017:241:249-54.

45. Fujiwara T, Yoshida M, Nakamura T, Sakakura K, Wada H, Arao K, Katayama T, Funayama H, Sugawara Y, Mitsuhashi T, et al. Dipeptidyl peptidase-4 inhibitors are associated with improved left ventricular diastolic function after acute myocardial infarction in diabetic patients. Heart Vessel. 2015; 30(5):696-701.

46. Zhao TC. Glucagon-like peptide-1 (GLP-1) and protective effects in cardiovascular disease: a new therapeutic approach for myocardial protection. Cardiovasc Diabetol. 2013;12:90.

47. Zhang X, Zhang Z, Yang Y, Suo Y, Liu R, Qiu J, Zhao Y, Jiang N, Liu C, Tse G, et al. Alogliptin prevents diastolic dysfunction and preserves left ventricular mitochondrial function in diabetic rabbits. Cardiovasc Diabetol. 2018:17(1):160.

48. Hirose M, Takano H, Hasegawa H, Tadokoro H, Hashimoto N, Takemura G, Kobayashi $Y$. The effects of dipeptidyl peptidase-4 on cardiac fibrosis in pressure overload-induced heart failure. J Pharmacol Sci. 2017;135(4):164-73.

49. Yamada H, Tanaka A, Kusunose K, Amano R, Matsuhisa M, Daida H, Ito M, Tsutsui $H$, Nanasato M, Kamiya $H$, et al. Effect of sitagliptin on the echocardiographic parameters of left ventricular diastolic function in patients with type 2 diabetes: A subgroup analysis of the PROLOGUE study. Cardiovasc Diabetol. 2017;16(1):1.

50. Liu Q, Anderson C, Broyde A, Polizzi C, Fernandez R, Baron A, Parkes DG. Glucagon-like peptide-1 and the exenatide analogue AC3174 improve cardiac function, cardiac remodeling, and survival in rats with chronic heart failure. Cardiovasc Diabetol. 2010;9:76.

51. Xiao YF, Nikolskaya A, Jaye DA, Sigg DC. Glucagon-like peptide-1 enhances voltage-gated Ca2+ currents of canine ventricular myocytes. J Card Fail. 2009;15(6):S72. 
52. Nguyen TD, Shingu Y, Amorim PA, SchenkI C, Schwarzer M, Doenst T. GLP-1 improves diastolic function and survival in heart failure with preserved ejection fraction. J Cardiovasc Transl Res. 2018;11(3):259-67.

53. Liu R, Li L, Chen Y, Yang M, Liu H, Yang G. Effects of glucagon-like peptide-1 agents on left ventricular function: systematic review and meta-analysis. Ann Med. 2014;46(8):664-71.

54. Huang M, Wei R, Wang Y, Su T, Li Q, Yang X, Chen X. Protective effect of glucagon-like peptide-1 agents on reperfusion injury for acute myocardial infarction: a meta-analysis of randomized controlled trials. Ann Med. 2017; 49(7):552-61.

55. Sacre JW, Jellis CL, Haluska BA, Jenkins C, Coombes JS, Marwick TH, Keske MA. Association of Exercise Intolerance in type 2 diabetes with skeletal muscle blood flow reserve. J Am Coll Cardiol Img. 2015;8(8):913-21.

\section{Publisher's Note}

Springer Nature remains neutral with regard to jurisdictional claims in published maps and institutional affiliations.

Ready to submit your research? Choose BMC and benefit from:

- fast, convenient online submission

- thorough peer review by experienced researchers in your field

- rapid publication on acceptance

- support for research data, including large and complex data types

- gold Open Access which fosters wider collaboration and increased citations

- maximum visibility for your research: over $100 \mathrm{M}$ website views per year

At BMC, research is always in progress.

Learn more biomedcentral.com/submissions 